\title{
Sob o signo da incerteza: autoridade simbólica e desamparo
}

\author{
Daniel Mograbi \\ Regina Herzog \\ Universidade Federal do Rio de Janeiro
}

\begin{abstract}
Resumo
Trabalha-se atualmente em psicanálise sobre a idéia de novas formas de patologias e novos sintomas que desafiariam a clínica psicanalítica, centrada em torno do conceito de recalque. Estes sintomas seriam representantes de processos de subjetivação que não se organizam a partir do referencial edipiano e encontrariam sua justificativa na idéia de uma autoridade simbólica em declínio. Neste trabalho, vamos investigar, por meio da noção de desamparo, de que forma Freud concebia a questão da interiorização da autoridade e da formação de uma instância moral no sujeito para, a partir daí, nos perguntar em que medida suas afirmações já denunciavam a crise da autoridade simbólica.
\end{abstract}

Palavras-chave: autoridade simbólica; desamparo; supereu; psicanálise

\begin{abstract}
Under the sign of uncertainty: symbolic authority and helplessness. The current work in psychoanalysis is on the idea of new forms of pathology and new symptoms that challenge the psychoanalytic practice, centered in the concepts of repressing. These symptoms would be representatives of subjectivities processes, which are not organized from the edipian reference, and they would find their justification in the idea of a symbolic authority in decline. In this work, we will investigate, through the notion of helplessness, by what form Freud conceived the authority's interiorization question and the shaping of the subject's moral instance and then ask ourselves in what proportion his posts had already considered the symbolic authority as little consistent and limited in its performance.
\end{abstract}

Keywords: symbolic authority; helplessness; super-ego; psychoanalysis

$\mathrm{O}$ bserva-se, na atualidade, uma gradual diminuição do prestígio da clínica psicanalítica, sendo esta questionada em suas possibilidades de intervenção e na pertinência de seus pressupostos teóricos. As mudanças culturais ocorridas no último século colocam em xeque o modelo freudiano do laço social, tal como sugerido em "Totem e tabu" (Freud, 1913/1996), no qual o sujeito se constitui a partir de processos identificatórios mediados por uma autoridade simbólica consistente. Em razão desses questionamentos há, hoje, na psicanálise, uma intensa produção voltada para o estudo da contemporaneidade e seus processos de subjetivação. Especula-se sobre novas doenças da alma (Kristeva, 2002), uma nova economia psíquica (Melman, 2003) e novas configurações do laço social (Zizek, 2003). Verificase, entre estes autores, um consenso na consideração de que o declínio da autoridade simbólica ${ }^{1}$ é uma das causas respon- sáveis, possivelmente o fator preponderante, pelo surgimento desses "novos" fenômenos.

Sabemos que, para a psicanálise, a questão da autoridade simbólica diz respeito à relação do sujeito com a lei, relação que só ganha a devida importância se considerada a partir da perspectiva de uma lei interiorizada; lei que se insere no processo de subjetivação como fator determinante. Ao longo de sua obra, Freud destaca algumas figuras para dar conta da idéia de uma moral interiorizada. Assim, encontramos em "As Neuropsicoses de Defesa” (1894/1996) a noção de defesa; em “A Interpretação dos Sonhos” (1900/1996), a censura; os diques de moralidade em "Três Ensaios sobre a sexualidade" (1905/1996); o ideal do eu apresentado em "Sobre o narcisismo: uma introdução" (1914/1996); e, a partir de "O eu e o isso" (1923/1996), o conceito de supereu. Todas estas construções conceituais funcionam dentro do registro de uma moral 
interiorizada, procurando dar suporte à concepção freudiana de autoridade simbólica.

O objetivo do presente trabalho é o de debruçar-se sobre essa questão, visando colocar a idéia de declínio da autoridade simbólica em perspectiva. Contudo, em virtude da amplitude do tema da moralidade na obra de Freud, optamos por fazer um recorte neste vasto universo conceitual. Assim, para empreender a investigação acerca da relação entre autoridade simbólica e uma instância crítica interna ao sujeito, propomos utilizar uma noção que se encontra no cerne desta dinâmica: a idéia de desamparo. Com isso, procuraremos mostrar qual o estatuto que Freud conferia à autoridade, precisar de que modo esta é interiorizada e, por fim, tentar responder a nossa principal interrogação: se Freud concebia ou não a autoridade simbólica como consistente e capaz, de fato, de ser fiadora do processo de constituição subjetiva.

Para tanto, destacamos três textos que permitem acompanhar a elaboração freudiana acerca desta problemática: “Sobre o narcisismo: uma introdução”, de 1914; “O Eu e o Isso”, de 1923 e "Mal Estar na Civilização”, de 1930. A partir destes artigos, vamos abordar a relação entre desamparo, a formação de uma instância crítica interna ao sujeito e a autoridade simbólica.

\section{Édipo e desamparo}

Com efeito, o texto "Sobre o narcisismo: uma introdução” (Freud, 1914/1996) vai situar a noção de desamparo no centro das discussões freudianas sobre a moralidade, marcando desde então as subseqüentes abordagens ao tema ${ }^{2}$. De início, podemos dizer que o conceito de narcisismo alavanca uma reconstrução nos tópicos da escolha amorosa e da relação entre a criança e seus pais, sendo que o impacto nestes dois pontos traz à tona a noção de desamparo. Acompanhemos a elaboração apresentada neste artigo.

Para Freud, o narcisismo corresponde ao instante em que toda libido está reunida em torno do eu. Este instante de concentração libidinal é o ponto de partida para o investimento em objetos. Ou seja, é somente através da passagem pelo narcisismo que o eu, com a libido agrupada em torno de si, pode investir nas representações dos objetos. Assim, o investimento libidinal original é direcionado para novos investimentos e, com isto, o sujeito vai saindo de um universo auto-referente para o reconhecimento de um universo externo. Entretanto, Freud não concebe o narcisismo como uma etapa superável dentro de um desenvolvimento cronológico $^{3}$. Suas manifestações atingem toda vida libidinal. A psicose ${ }^{4}$, por exemplo, corresponderia ao retorno da libido para o eu, e existem outros casos, fora do campo da psicopatologia, em que o narcisismo atua de forma decisiva: a escolha amorosa é um deles.

Freud vai mostrar que, com freqüência, os objetos de amor são selecionados a partir de uma opção narcisista. As pessoas buscam, em seus relacionamentos, a si mesmas, o que foram um dia, ou o que gostariam de ser. Certamente há o investimento em um objeto, mas trata-se de um investimento que retira sua força da libido do eu e está condiciona- do ao narcisismo. O narcisismo vai ceder diante do aumento progressivo dos investimentos objetais, sem, no entanto, deixar de se fazer presente nestes mesmos investimentos. Com isso, Freud promove uma reviravolta conceitual nas idéias contidas nos dois primeiros artigos do que chamou de “Contribuições à psicologia do amor” (1910/1996; 1912/ 1996). As escolhas amorosas de base narcísica sugerem a importância do narcisismo na constituição subjetiva; podemos mesmo dizer que estas escolhas colocam o narcisismo como ponto de balizamento de um modo de subjetivação (Pinheiro \& Herzog, 2003). Neste sentido, a relação do sujeito com o outro passa a carregar a marca indelével de um narcisismo que é, ele próprio, a condição de possibilidade desta relação; nas palavras de Freud, "há um investimento libidinal original do eu, parte do qual é posteriormente transmitido a objetos" (1914/1996, p. 83).

Vejamos, agora, como o investimento objetal nos pais e sua relação com a libido narcísica tem pertinência destacada em nossa discussão. As figuras parentais, ou qualquer substituto que represente a autoridade, serão investidas a partir da libido do eu, caracterizando-se como uma aspiração da criança, que vai se esforçar para alcançar os seus atributos. Em outras palavras, o investimento objetal nos pais representará o que narcisicamente gostariam de ser. Os pais se apresentam como modelos na medida em que fazem exigências para a criança, por meio de injunções e proibições, e ofertam seu amor de acordo com o cumprimento da lei que impõem. A criança desobediente é repreendida, ao passo que aquela que se conforma às ordens é elogiada e premiada com o carinho dos pais. Isto faz com que a satisfação narcísica seja cada vez mais atingida pela realização das imposições parentais. Forma-se, no eu, uma diferenciação pela interiorização dos ditames culturais, um ideal que "as pessoas se esforçam por atingir como sendo sua felicidade” (Freud, 1914/1996, p. 107).

A constituição deste ideal é o passo que caracteriza a entrada do sujeito na lei externa. Há uma idealização do eu a partir da influência dos pais e esta idealização servirá como parâmetro de comparação para o eu. Em razão disto, Freud afirma que o ideal do eu "é o fator condicionante do recalque" (1914/1996, p. 100), ou seja, apenas com o surgimento desta instância é possível afirmar o que é inaceitável, incompatível, declarado como imoral para o sujeito. Para explicitar o funcionamento do ideal, Freud se vale de um recurso que lhe é familiar: diluindo a distinção entre normalidade e patologia, demonstra que entre as atribuições do ideal estão a auto-observação e a autocrítica. Os distúrbios paranóides, quadros marcados por delírios e alucinações auditivas persecutórias, apontam para o exemplo extremo do funcionamento do ideal, com a diferença de que na paranóia perde-se a capacidade de discriminar o eu do mundo. A atividade do ideal, que na psicose é manifesta, acontece de forma velada na neurose. Mais ainda, as alucinações auditivas dos paranóides servem para indicar de que forma a autocrítica atua: por meio das representações sonoras. Deste modo, o não da autoridade, dos pais ou substitutos, dará lugar ao não do agente crítico. A descrição popular do re- 
morso e dos escrúpulos como voz da consciência encontra aqui uma justificativa.

A postulação de um ideal, que tem seu surgimento e funcionamento de acordo com o percurso descrito acima, sugere uma certa dinâmica psíquica, marcada pelo desamparo. A passagem do narcisismo para o investimento objetal é o momento de entrada no mundo, mediado pela autoridade simbólica. Conforme já assinalado, esta passagem se dá a partir de uma renúncia movida pela ameaça de perda de amor, ou seja, a criança investe no outro em busca de resposta, que viria sob a forma de uma oferta de amor. É somente nestas condições que "Sua Majestade, o Bebê" se rende à lei do outro; em outras palavras, a saída do autocentramento narcísico, por meio da constituição de um ideal, se justifica pela noção de desamparo.

Quase dez anos depois da publicação deste texto, Freud retoma a questão da constituição do ideal em "O eu e o isso" (1923/1996), munido, desta vez, de uma nova e importante ferramenta: o conceito de identificação. Na verdade, este termo já era utilizado desde os primórdios da psicanálise, mas somente a partir da década de 1910, Freud vai conferir-lhe um estatuto conceitual. Isto aparece especialmente a partir das discussões que empreende em "Totem e tabu”, quando aborda a identificação dos irmãos com o pai da horda, e em "Luto e melancolia” (1917/1996), onde é tematizada a identificação com o objeto perdido. Após 1921, o termo ganha contornos mais precisos e Freud chega a dedicar um capítulo do texto “Psicologia das Massas e Análise do Eu” (1921/1996) para explicitá-lo, alçando-o à categoria de conceito.

O conceito de identificação traz uma nova perspectiva para o entendimento da rede de investimentos eróticos e de rivalidade que formava o complexo de Édipo. Conforme indicado acima, os filhos tomarão os pais como objetos de amor e a formação de um ideal na criança surge a partir das exigências feitas a ela e da oferta de amor - por parte dos pais pautada pelo cumprimento destas exigências. A formação do ideal representa a constituição de um modelo a ser seguido, sendo este ideal o fator condicionante do recalcamento. Contudo, não podemos desprezar o fato de que o ideal também se alimenta dos impulsos sexuais. Ou seja, o recalcamento, que empurra impulsos sexuais para o inconsciente, surge às expensas da energia erótica dirigida para as figuras parentais. Em algum momento, a atividade erótica cedeu energia para a formação de um ideal, ideal este que passou a censurar os impulsos sexuais dos quais é devedor.

Sabemos que o narcisismo, com a concentração da libido no eu, foi o ponto de partida para o investimento nos objetos. As primeiras vinculações emocionais com objetos - tomados em sua totalidade - surgem nessa época. O instante da passagem da libido narcísica para a libido objetal pode ser considerado o marco inicial do complexo de Édipo, nome usado por Freud para descrever o intrincado campo de relações da criança com seus pais. Nestes termos, o complexo de Édipo diz respeito justamente ao resultado dos investimentos objetais e identificações deste período em que a criança deixa de amar apenas a si e passa a amar os outros.
Em sua forma simples ${ }^{5}$, esta rede de investimentos articula-se da seguinte forma: na luta pela exclusividade do amor materno, o menino rivaliza com o pai, ao mesmo tempo em que se identifica com ele, tentando ser como aquele que tem a mãe. Contudo, os desejos edípicos esbarram em uma forte proibição cultural, a interdição ao incesto. Diante desta barreira que impede a realização dos anseios infantis, condenando o assassinato do pai para a tomada da mãe como mulher, o complexo de Édipo sucumbe. O seu desfecho é sempre infortunado, a proscrição do incesto leva ao recalcamento dos impulsos com este caráter, e institui a consciência e a moralidade.

O investimento objetal nos pais frustra-se e cede espaço para identificações; a criança, na tentativa de reter os objetos de amor que perdeu, molda-se à imagem deles, oferecendo-se ao isso como um objeto de amor. A identificação no eu seria um mecanismo para lidar com a perda dos objetos, e indicaria uma relação de dependência para com o outro. Como Freud afirma, "talvez seja a única condição em que o isso pode abandonar os seus objetos” (1923/1996, p. 42), ou seja, o eu identificado com o objeto assume o espaço vazio deixado por este. A autoridade das figuras parentais será introjetada formando o núcleo do supereu e as tendências sexuais serão abandonadas, sublimadas para aquisições culturalmente aceitas ou convertendo-se em ternura pela inibição de sua meta.

A ameaça de perda de amor, então, se inscreve tanto na saída do narcisismo, quanto no insucesso das primeiras tentativas de investimento objetal, dirigidas para os pais. Estes dois momentos marcam o desenrolar da situação edípica: o afastamento do narcisismo, correspondendo ao início do triângulo edípico e a ameaça de castração, culminando em sua dissolução. Mostra-se, aí, a importância do desamparo no processo de subjetivação. Para além do momento edipiano, esta importância também aparece quando Freud, no mesmo texto, sublinha que de fato a identificação da criança com os pais independe de um investimento objetal: "trata-se de uma identificação direta e imediata, e se efetua mais primitivamente do que qualquer investimento de objeto" (1923/1996, p. 44). Esta afirmação parece remeter diretamente à problemática do desamparo, aspecto que merece ser abordado.

\section{As faces do desamparo em Freud}

Algumas passagens de Freud, em particular, podem fornecer recursos para pensarmos o estatuto da identificação primária em face da noção de desamparo. Ele afirma, por exemplo, em "Três ensaios sobre a sexualidade" que "durante todo o período de latência a criança aprende a amar outras pessoas que ajudam em seu desamparo e satisfazem suas necessidades, e o faz segundo o modelo de sua relação de lactente com a ama” (1905/1996, p. 210, nosso grifo); ou, ainda, no texto sobre o narcisismo diz que "os primeiros objetos sexuais de uma criança são as pessoas que se preocupam com sua alimentação, cuidados e proteção” (1914/1996, p. 94, nosso grifo). Freud está dando ênfase, aqui, ao caráter especial da relação do bebê com seus cuidadores, uma relação atravessada pela sexualidade sem haver, contudo, um investimento 
objetal. Desta primitiva relação, capaz de emitir ecos nas escolhas objetais e identificações posteriores, deriva a identificação primária: uma identificação construída a partir do diferencial prazer/desprazer, atravessada, portanto, pela sexualidade auto-erótica do bebê. Não podemos nos esquecer, que a sexualidade auto-erótica tem como condição de possibilidade a presença do outro.

Todavia, cabe esclarecer que neste caso trata-se do desamparo referido simplesmente à incapacidade do neo-nato de satisfazer suas próprias necessidades, à impossibilidade, nos termos do "Projeto para uma psicologia científica" (Freud, 1895/1996), do recém-nascido realizar a ação específica capaz de minorar o desprazer por meio de uma alteração na realidade externa. Apesar de Freud não abandonar esta perspectiva inicial de um desamparo objetivo e referido a um momento pontual, o desenvolvimento da noção aponta para um alargamento de seus horizontes, sendo cada vez mais valorizada em sua dimensão de falta de garantias e limite da simbolização ${ }^{6}$, como veremos adiante. Sem desmerecer este momento inicial de Freud, entendemos, entretanto, que a visão ulterior fornece mais subsídios para a discussão da interiorização da moral.

Nesta perspectiva, pouco a pouco Freud vai aproximar a noção de desamparo da questão do anseio pelo pai. Com efeito, o pai é o responsável pela coesão do grupo, na medida em que dá a seus membros uma filiação em comum, algo em torno do que seus filhos possam estabelecer uma identificação que os una. Já em “Totem e tabu” (1913/1996), este papel é sublinhado, quando se refere à constituição dos diversos clãs totêmicos. O totem, símbolo do pai primevo, opera não só como uma marca da ancestralidade em comum dos membros do clã, como também é responsável pela atribuição dos lugares do sagrado e do profano.

Neste sentido, podemos pensar no pai como o norte na bússola moral dos grupos. Nos termos utilizados em "Psicologia das massas e análise do eu” (Freud, 1921/1996), o representante paterno, líder ou idéia que ocupe este lugar, é o ideal do grupo. A que se deve esta posição estratégica ocupada pelo pai na vida libidinal da massa? No final do quarto ensaio de “Totem e tabu” (1913/1996), Freud traça uma linha que vai do totemismo às formações religiosas mais complexas, em especial o judaísmo e o cristianismo, demonstrando que a persistência da idéia de um deus todo poderoso alude ao pai da horda, ilimitado em sua força e por isso mesmo temido e admirado. No entanto, a questão da religião não é central nesse texto, tendo sido analisada mais como uma consequência que endossa o mito freudiano. Vai ser somente em “O futuro de uma ilusão” (Freud, 1927/1996), que ela será tratada em toda sua amplitude.

O fio condutor desse trabalho é a questão que inicia o terceiro capítulo: "Em que reside o valor peculiar das idéias religiosas?” (1927/1996, p. 24). A resposta, já dada no título do ensaio, é incisiva: as religiões são ilusões, "realizações dos mais antigos, fortes e prementes desejos da humanidade” (1927/1996, p. 39). O que torna as idéias religiosas poderosas é o anseio por um pai poderoso e protetor, um deus capaz de resguardar os homens das intempéries da natureza, reconciliá-los com as exigências culturais e fornecer uma alternativa ao terrificante e irrepresentável da morte. O que se encontra velado nos deuses das mais variadas formações religiosas é a figura do pai da horda, tomado em seu aspecto idealizado. Os homens precisam do pai protetor, “de proteção através do amor” (1927/1996, p. 39), em razão de um infantilismo que perdura na vida adulta. Aqui fica bem marcada a passagem da idéia de um desamparo pontual para a de um desamparo inerente à condição humana ${ }^{7}$. A infância e, a reboque, o desamparo, não é superável, persiste como o modo de relação do homem com as forças imperiosas da natureza, e sobretudo com a morte.

Todavia, ao passo que implicitamente o desamparo é alargado em seus horizontes, “O futuro de uma ilusão” (1927/ 1996) é também um texto notório pela defesa insistente realizada por Freud quanto à possibilidade de progresso social e do sujeito, colocando-se como ardoroso partidário dos ideais científicos e modernos. Esta ambiguidade deve ser sublinhada, especialmente porque se trata de um texto que se situa entre "Totem e tabu”(1913/1996) e "Mal estar na civilização”(1930/1996), ainda que cronologicamente mais próximo deste último. Se em 1913 Freud acredita na idéia de consumação do processo civilizatório, esta perspectiva é abandonada em 1930 (Farah \& Herzog, 2005). Em “O futuro de uma ilusão” (1927/1996), a posição de Freud sobre a questão é cambiante. O que nos autorizaria, então, uma leitura, deste texto, que privilegie o desamparo em sua dimensão não ultrapassável?

Acreditamos que o recorrente recurso a um opositor imaginário que ataca seus pontos de vista é representativo de toda divisão de Freud em relação ao tema. De fato, e especialmente nos últimos capítulos, o opositor imaginário parece ter mais consistência em seus argumentos, demonstrando inclusive mais coerência com o conjunto da obra psicanalítica. Opositor imaginário, freudiano em seus argumentos, estranho familiar, que coloca uma aura de dúvida na possibilidade de superação do infantilismo.

Além disso, também podemos nos autorizar com o fato de Freud ter optado por tratar a questão a partir deste viés apenas três anos depois, em "Mal estar na civilização” (1930/ 1996), primeiro grande texto após “O Futuro de uma ilusão" (1927/1996), com a afirmação peremptória da insuperabilidade do infantilismo.

Ainda que seja certo que Freud é muito incisivo ao afirmar sua oposição às ilusões, não podemos esquecer seu posicionamento sui generis diante da ciência da época. Mesmo que com a invenção da psicanálise tivesse rompido com os ideais positivistas, estes foram, dentre outros ${ }^{8}$, algumas das raízes de seu pensamento, sendo o texto de "O futuro de uma ilusão” (1927/1996) uma autêntica formação de compromisso, em que defende a ciência para em seguida atacá-la sob a forma do opositor imaginário. Além disto, quando Freud defende a ciência diante das ilusões, tenta fazê-lo considerando a ciência como um processo de desilusão, um processo penoso que repõe para o sujeito as indesejáveis verdades que ele tentava evitar. Parece que a concepção freudiana de 
ciência é bastante singular e pouco tem a ver com os ideais positivistas. De fato, quem desvela as ilusões e propõe sustentar o mal estar, não é outra senão a psicanálise.

Dessa forma, chegamos a "Mal estar na civilização" (1930/ 1996), a partir do reposicionamento da idéia de desamparo. Entretanto, há um outro caminho para abordarmos este texto. Para além da radicalização da noção de desamparo, podemos alcançá-lo por uma outra via, também pertinente em nossa discussão: trata-se da articulação entre desamparo e agressividade. Em “O eu e o isso” (1923/1996), Freud vai relacionar a trama de investimento objetal com a constituição da instância crítica, bem como a pulsão de morte com a atuação destrutiva do supereu quando discute a reação terapêutica negativa, mas não chega a fazer uma ponte entre esses dois temas. Depois, em textos como "O problema econômico do masoquismo" (1924/1996b) e "Dostoievski e o parricídio" (1928/1996), começa a estabelecer, gradativamente, o elo entre anseio pelo pai e ódio ao pai. Porém, somente em "Mal estar na civilização” (1930/1996) vai se dedicar à questão, expondo com mais clareza a relação entre agressividade, supereu e desamparo.

Assim, é por meio de uma dupla entrada - a de uma radicalização da noção de desamparo e a de sua articulação com a agressividade -, que abordamos o texto de 1930. Em realidade, não se trata de dois caminhos paralelos, mas duas linhas que se cruzam, formando o cerne das questões desenvolvidas por Freud neste trabalho.

O texto inicia-se com a réplica a Romain Rolland sobre o estatuto do sentimento oceânico, uma suposta sensação de completude e eternidade em comunhão com o universo. Freud recusa-o enquanto um sentimento primário, fazendo-o remontar ao desamparo infantil. Aqui, ele refaz a construção sobre a experiência primária de satisfação, apontando que é a necessidade de um outro que possibilita a gradual distinção entre o eu e o mundo. É importante frisar que essa distinção vai se formando a partir do movimento pendular de ausência e presença do outro necessário; um outro sempre presente ou sempre ausente de forma alguma seria propiciador da constituição dessa fronteira.

Sendo assim, Freud relaciona o sentimento oceânico ao desamparo infantil, considerando este último a fonte das necessidades religiosas. Lançando mão da analogia da sobrevivência, na cidade de Roma, de fragmentos de suas estruturas históricas, Freud vai afirmar a persistência do desamparo infantil. Este não é destruído e, ainda que soterrado, forma a base sobre a qual se erige a nova cidade.

Desta forma, a superação das ilusões não se mostra tão evidente e inevitável como Freud havia proposto em algumas passagens de “O futuro de uma ilusão" (1927/1996). Além disto, faz parte da condição humana uma trinca de sofrimentos capaz de desarticular qualquer pretensão de felicidade: o homem sofre pelo próprio corpo, fonte de sensações desprazerosas e em marcha inexorável para a decadência; é afligido pelas forças esmagadoras da natureza, que causam dor e morte; e padece, de forma ainda mais penosa, no relacionamento com outros homens.
Com relação a este último, o impacto da agressividade se faz sentir jogando por terra qualquer pretensão de convivência harmoniosa; trata-se de pura ilusão. Há uma hostilidade inerente ao homem, e o próximo é aquele que nos incita a "satisfazer sobre ele sua agressividade, a explorar sua capacidade de trabalho sem compensação, utilizá-lo sexualmente sem o seu consentimento, apoderar-se de suas posses, humilhá-lo, causar-lhe sofrimento, torturá-lo e matá-lo” (Freud, 1930/1996, p. 116).

Fica marcada, com esta passagem, a delicadeza da relação com o outro, uma relação repleta de riscos e carente de garantias, sobretudo no que concerne ao impacto da violência no trato entre os homens. Não há laço social ou pacto simbólico capaz de resguardar o sujeito da ação destrutiva do outro. Freud sublinha, até mesmo, os limites da linguagem, e de suas construções ilusórias, no resguardo das relações com o outro. Há um desamparo próprio a essa falha simbólica, resultado da desilusão a que este pacto simbólico remete, e da desproteção a que o sujeito é lançado, por se sentir despido de suas ilusões, diante de um outro desejante e destrutivo.

Nesse contexto, podemos entender o desenvolvimento de uma instância moral no sujeito a partir de uma nova perspectiva: a lei é interiorizada não só pelo amor, mas também pelo terror. O sujeito desamparado, diante da violência do outro, acata sua lei para não ser destruído, submete-se tendo em vista a falta de uma regulação consistente em sua relação com este outro, que dessa forma se apresenta terrificante.

No entanto, é importante frisar que o impacto da agressividade nas relações humanas também se dá no sentido inverso: do sujeito para a autoridade. Além de ser coercitiva e capaz de impor-se pela força, a autoridade também pode ser atacada pelo sujeito, alvo de sua ira e de seus impulsos destrutivos. Aqui, Freud dá ampla expressão à idéia de um ódio ao pai, já em germe em “Totem e tabu” (1913/1996), mas só levada às últimas conseqüências em 1930. A única forma de controlar a agressividade é por meio de formações reativas, que subvertem o impulso destrutivo para os objetivos culturais. Como já vimos, o sujeito é introduzido na ordem simbólica pela via do desamparo; a autoridade, quando consistente, é interiorizada formando uma instância crítica que pode, então, utilizar a força da pulsão de morte ${ }^{9}$ para controlar o sujeito em suas ações, vigiando-o e punindo-o. A agressividade do supereu é a agressividade que outrora foi dirigida contra a autoridade, mas que agora se encontra a serviço dela, submetendo o sujeito a seus preceitos por meio do sentimento de culpa.

Nesta operação, há um resto de agressividade que não é assimilado: a destrutividade que sobra na relação com o outro permanece no supereu, não simbolizada e sempre presente. Disso, do pulsional, não se escapa, por mais potentes que sejam as ilusões criadas: a ilusão do ideal do eu, da crença na regulação da autoridade e no pacto simbólico. A agressividade retorna nos excessos do supereu, acuando o eu tal qual uma criança diante dos pais, para nos valermos de uma metáfora freudiana. 


\section{Uma aposta incerta}

É diante destas considerações que tecemos a partir dos textos mencionados, que nos perguntamos em que medida, já em Freud, a autoridade simbólica era apresentada em sua falta de consistência, e o percurso da interiorização da moral era visto como um caminho cheio de percalços, não havendo ao fim garantias sólidas em relação ao outro e aos excessos do supereu. Longe de desprezarmos as mudanças sociais ocorridas desde então, entendemos que uma direção para encaminhar os diversos questionamentos atuais se encontra presente nos textos de Freud, especialmente no que concerne à noção de desamparo.

Cabe ao analista contemporâneo decidir se deve ou não apostar na atualidade da teorização freudiana para dar conta dos desafios, constantes, que se apresentam para a prática clínica.

\section{Referências}

Farah, B. L. \& Herzog, R. (2005). (no prelo). A psicanálise e o futuro da civilização moderna. Psyché.

Freud, S. (1996). As neuropsicoses de defesa. In Edição standard brasileira das obras completas de Sigmund Freud (Vol. III). Rio de Janeiro: Imago. (Texto original publicado em 1894)

Freud, S. (1996). Projeto para uma psicologia científica. In Edição standard brasileira das obras completas de Sigmund Freud (Vol. III). Rio de Janeiro: Imago. (Texto original publicado em 1895)

Freud, S. (1996). A interpretação dos sonhos. In Edição standard brasileira das obras completas de Sigmund Freud (Vols. IV e V). Rio de Janeiro: Imago. (Texto original publicado em 1900)

Freud, S. (1996). Três ensaios sobre a sexualidade. In Edição standard brasileira das obras completas de Sigmund Freud (Vol. VI). Rio de Janeiro: Imago. (Texto original publicado em 1905)

Freud, S. (1996). Contribuições à psicologia do amor I. In Edição standard brasileira das obras completas de Sigmund Freud (Vol. XI). Rio de Janeiro: Imago. (Texto original publicado em 1910)

Freud, S. (1996). Caso Schreber. In Edição standard brasileira das obras completas de Sigmund Freud (Vol. XII). Rio de Janeiro: Imago. (Texto original publicado em 1911)

Freud, S. (1996). Contribuições à psicologia do amor II. In Edição standard brasileira das obras completas de Sigmund Freud (Vol. XI). Rio de Janeiro: Imago. (Texto original publicado em 1912)

Freud, S. (1996). Totem e tabu. In Edição standard brasileira das obras completas de Sigmund Freud (Vol. XIII). Rio de Janeiro: Imago. (Texto original publicado em 1913)

Freud, S. (1996) Sobre o narcisismo: uma introdução. In Edição standard brasileira das obras completas de Sigmund Freud (Vol. XIV). Rio de Janeiro: Imago. (Texto original publicado em 1914)
Freud, S. (1996). Luto e melancolia. In Edição standard brasileira das obras completas de Sigmund Freud (Vol. XIV). Rio de Janeiro: Imago. (Texto original publicado em 1917 [1915])

Freud, S. (1996) Psicologia das massas e análise do eu. In Edição standard brasileira das obras completas de Sigmund Freud (Vol. XVIII). Rio de Janeiro: Imago. (Texto original publicado em 1921)

Freud, S. (1996). O eu e o isso. In Edição standard brasileira das obras completas de Sigmund Freud (Vol. XIX). Rio de Janeiro: Imago. (Texto original publicado em 1923)

Freud, S. (1996a). A dissolução do complexo de Édipo. In Edição standard brasileira das obras completas de Sigmund Freud (Vol. XIX). Rio de Janeiro: Imago. (Texto original publicado em 1924)

Freud, S. (1996b). O problema econômico do masoquismo. In Edição standard brasileira das obras completas de Sigmund Freud (Vol. XIX). Rio de Janeiro: Imago. (Texto original publicado em 1924)

Freud, S. (1996) Algumas conseqüências psíquicas da diferença anatômica entre os sexos. In Edição standard brasileira das obras completas de Sigmund Freud (Vol. XIX). Rio de Janeiro: Imago. (Texto original publicado em 1925)

Freud, S. (1996). Inibições, sintomas e angústia. In Edição standard brasileira das obras completas de Sigmund Freud (Vol. XIX). Rio de Janeiro: Imago. (Texto original publicado em 1926)

Freud, S. (1996). O futuro de uma ilusão. In Edição standard brasileira das obras completas de Sigmund Freud (Vol. XXI). Rio de Janeiro: Imago. (Texto original publicado em 1927)

Freud, S. (1996). Dostoievski e o parricídio. In Edição standard brasileira das obras completas de Sigmund Freud (Vol. XXI). Rio de Janeiro: Imago. (Texto original publicado em 1928)

Freud, S. (1996). Mal estar na civilização. In Edição standard brasileira das obras completas de Sigmund Freud (Vol. XXI). Rio de Janeiro: Imago. (Texto original publicado em 1930)

Gerez-Ambertín, M. (2003). As vozes do supereu: na clínica psicanalítica e no mal-estar na civilização. São Paulo: Cultura Ed. Associados; Caxias do Sul: EDUCS.

Kristeva, J. (2002). As novas doenças da alma. Rio de Janeiro: Rocco.

Lacan, J. (1992). O seminário - Livro VIII - A transferência. Rio de Janeiro: Jorge Zahar.

Lo Bianco, A. C. (1998). A bildung alemã e a cultura em Freud. In N. Sampaio (Org.), Cultura da Ilusão - IV Fórum Brasileiro de Psicanálise (pp. 65-80). Rio de Janeiro: Contracapa.

Melman, C. (2003). O homem sem gravidade. Rio de Janeiro: Companhia de Freud.

Pereira, M. E. (1999). Pânico e desamparo: um estudo psicanalítico. São Paulo: Escuta.

Pinheiro, T., \& Herzog, R. (2003, novembro). Impasses na clínica psicanalítica: a invenção da subjetividade. Comunicação apresentada no $2^{\underline{0}}$ Encontro Mundial dos Estados Gerais da Psicanálise, Rio de Janeiro, Brasil.

Zizek, S. (2003). Bem-vindo ao deserto do real. São Paulo: Boitempo. 
${ }^{1}$ Lacan, no tópico "O mito de Édipo hoje - um comentário da trilogia dos Coûfontaine, de Paul Claudel” (Seminário Livro 8 - A transferência, 1992/1960-61), analisa a tragédia contemporânea, ressaltando a figura do pai humilhado, figura bastante diversa daquela introduzida no mito de origem da sociedade (Freud, 1913/ 1996). É nesse contexto que podemos situar a expressão declínio da autoridade simbólica.

${ }^{2}$ Em 1895, no texto "Projeto para uma psicologia científica”, Freud já havia antecipado a idéia de que o desamparo é a fonte de todos os motivos morais (1895/1996, p. 370). Contudo, conforme indica GerezAmbertín (2003), neste momento de sua obra, Freud ainda não havia abordado consistentemente a idéia de uma instância crítica interna ao sujeito.

${ }^{3}$ É importante frisar que, antes de 1914, Freud utiliza o termo narcisismo, ainda que sem o estatuto de um conceito. Nesta acepção anterior, presente na $2^{\underline{a}}$ edição dos "Três ensaios sobre a sexualidade" (1905/1996), no “Caso Schreber” (1911/1996) e em “Totem e Tabu” (1913/1996), o narcisismo é considerado apenas enquanto uma etapa do desenvolvimento.

${ }^{4}$ Freud utiliza o termo parafrenia neste momento de sua obra.

${ }^{5}$ Para o desenvolvimento da presente discussão, não se faz necessário descrever a forma invertida do complexo de Édipo. Remetemos o leitor para “Algumas conseqüências psíquicas da distinção anatômica entre os sexos” (Freud, 1925/1996) e “A dissolução do complexo de Édipo” (Freud, 1924/1996a).

${ }^{6}$ A discussão sobre as perspectivas diferentes adotadas por Freud no tocante à noção de desamparo teve como referência o livro "Pânico e desamparo" (Pereira, 1999).

${ }^{7}$ A mudança das concepções freudianas sobre a angústia é correlata à complexificação da noção de desamparo. Ao considerar que a angústia é causa e não consequência do recalcamento (1926/1996), Freud enfatiza o desamparo fundamental e constituinte do sujeito.

${ }^{8}$ Para uma referência mais completa sobre as condições de surgimento da psicanálise, remetemos para Lo Bianco (1998).

${ }^{9}$ Quando usamos o termo pulsão de morte, estamos nos referindo a um modo de funcionamento da pulsão, e não a uma pulsão qualitativamente diferente.

Daniel Correa Mograbi é mestre em Teoria Psicanalítica pela Universidade Federal do Rio de Janeiro. Endereço para correspondência: Rua Visconde de Pirajá, 206, apto. 201 (Ipanema); Rio de Janeiro, RJ; CEP 22410-000. Tel.: (21) 2513-4479. E-mail: dmograbi@hotmail.com

Regina Herzog de Oliveira, doutora em Psicologia Clínica pela Pontifícia Universidade Católica do Rio de Janeiro, é professora no Programa de Pós-graduação em Teoria Psicanalítica da Universidade Federal do Rio de Janeiro. E-mail: rherzog@globo.com 